\title{
ON SPECIAL DIFFERENTIAL SUBORDINATIONS USING SĂLĂGEAN AND RUSCHEWEYH OPERATORS
}

\author{
Alina Alb LupaŞ
}

Abstract. In the present paper we define a new operator using the Sălăgean and Ruscheweyh operators. By $L_{\alpha}^{n}$ we denote the operator given by $L_{\alpha}^{n}: A \rightarrow A, L_{\alpha}^{n} f(z)=(1-\alpha) R^{n} f(z)+$ $\alpha S^{n} f(z)$, for $z \in U$, where $R^{n} f(z)$ denotes the Ruscheweyh derivative, $S^{n} f(z)$ is the Sălăgean operator and $A_{n}=\left\{f \in \mathscr{H}(U): f(z)=z+a_{n+1} z^{n+1}+\ldots, z \in U\right\}$ is the class of normalized analytic functions with $A_{1}=A$. A certain subclass, denoted by $S_{n}(\delta, \alpha)$, of analytic functions in the open unit disc is introduced by means of the new operator. By making use of the concept of differential subordination we derive various properties and characteristics of the class $S_{n}(\delta, \alpha)$. Also, several differential subordinations are established regarding the operator $L_{\alpha}^{n}$.

Mathematics subject classification (2000): 30C45, 30A20, 34A40.

Keywords and phrases: Differential subordination, convex function, best dominant, differential operator.

\section{REFERENCES}

[1] A. AlB Lupaş, Some differential subordinations using Sălăgean and Ruscheweyh operators, Proceedings of International Conference on Fundamental Sciences, ICFS 2007, Oradea, 58-61.

[2] A. CăTAŞ, On univalent functions defined by a generalized Sălăgean operator, Studia Univ. BabesBolyai Math, Volume LIII, 2 (2008), 29-34.

[3] A. C̆̆TAŞ, A note on subclasses of univalent functions defined by a generalized Sălăgean operator, ROMAI Journal, 3, 1 (2007), 47-52.

[4] S.S. Miller, P.T. Mocanu, Differential Subordinations. Theory and Applications, Marcel Dekker Inc., New York, Basel, 2000.

[5] St. Ruscheweyh, New criteria for univalent functions, Proc. Amet. Math. Soc., 49 (1975), 109-115.

[6] G. ST. SăLĂGEAN, Subclasses of univalent functions, Lecture Notes in Math., Springer Verlag, Berlin, 1013 (1983), 362-372. 